\title{
Horácio E AdÉlia PRAdo: DoIS Momentos do CARPE DIEM
}

\section{Horácio and Adélia Prado: two moments of the carpe diem}

\author{
Cristian Pagoto* \\ Juliana Alves Barbosa Menezes** \\ Mirele Carolina Werneque Jacomel***
}

\begin{abstract}
Segundo o poeta italiano Leopardi "Tudo se aperfeiçoou de Homero em diante, mas não a poesia". o que equivaleria dizer, em termos gerais, que a poesia é a mesma de antigamente, que ela nos fala a mesma coisa sempre, que os poemas são imitações de outros poemas. Seria, portanto, exato e inequívoco falar em ruptura? Se a poesia permanece a mesma e há uma continuidade, como explicar o binômio paradoxal - vastamente discutido nos círculos teóricos atuais - tradição/modernidade, ou em outros termos, tradição/ruptura? Se a tradição implica continuidade e repetição, e modernidade pressupõe ruptura e novidade, em que margem está a poesia lírica contemporânea?

A modernidade proclamou o novo e este passou a ser a medida para valorizar uma obra. Se antes a imitação de modelos e formas literárias nutria a inspiração dos artistas, agora é a ideia de originalidade que os guia. Mas até que ponto uma obra pode ser considerada original? Existe originalidade? E se de fato esta existe, como poderia ser formulada a relação entre o leitor e o texto? O leitor apenas reconhece textos com os quais pode manter uma relação de diálogo com outros textos já lidos. Assim, todo texto retoma outro, num processo ad infinitum "até o momento em que tudo se parece com tudo, graças ao pai Adão" (PERRONE-MOISÉS, 1973, p. 79).
\end{abstract}

\footnotetext{
Mestra em Letras - Universidade Estadual de Maringá.

Mestra em Letras - Universidade Estadual de Maringá

Doutoranda em Letras - Universidade Estadual de Londrina.
} 
Diante de tais questionamentos, procuraremos investigar a relação atual da literatura, especificamente da poesia brasileira, com a tradição e a ruptura. Partiremos de um estudo sobre a genealogia do carpe diem, de Homero até Horácio, o representante maior desse gênero. Assim, teremos suporte necessário para estabelecer as relações de comparação entre o texto de Horácio, ad Leuconoen, e o poema de Adélia Prado, $O$ encontro.

A história literária oscila sempre entre dois terrenos igualmente minados: tradição e ruptura. A discussão sobre a existência e a permanência de uma tradição literária ou sobre a afirmação de uma ruptura estética com essa tradição e com todo um passado textual, edificada em idolatria a partir do Romantismo, suscita também uma série de outros binômios paradoxais: imitação/inovação, classicismo/romantismo, antigos/modernos. Estes, talvez, podem ser resumidos e entrelaçados no binômio mencionado acima, o que infelizmente não nos esclarece muita coisa, muito menos facilita nosso trabalho em entender a história da literatura.

Ao lado dessas dicotomias temos dois pontos de vista contraditórios sobre as obras literárias: a visão sincrônica e universal da literatura, que vê as obras literárias como simultâneas e contemporâneas entre si e para seus leitores - assim, a história e a distância temporal tornam-se irrelevantes - e o ponto de vista diacrônico e relativista, que entende a literatura como uma sucessão cronológica e, portanto, parte de um processo histórico. "É a distinção entre monumento e documento. Ora, a obra de arte é eterna e histórica. Paradoxal por natureza, irredutível a um de seus aspectos, é um documento histórico que continua a proporcionar uma emoção estética" (COMPAGNON, 1996, p. 202). Isto quer dizer que ao mesmo tempo em que a literatura é texto historicamente datável, pertencente a uma época, ela é eterna e pode ser presentificada em cada leitura, tornando-se sempre contemporânea e atual.

Para Perrone-Moisés (1998, p. 27) "a história literária desenvolveuse como a história dos Pais da Literatura”. A tradição literária passou a ser vista como "fonte de ensinamentos" e os modernos deveriam voltar os olhos para os antigos, como uma espécie de dívida ou submissão a eles, relembrando a antiga imagem de Bernard de Chartres: os anões (moderni) sentados nos ombros de gigantes (antiqui). "Os grandes escritores do passado seriam os Pais e Mestres, que os novos escritores deveriam honrar e imitar" (PERRONE-MOISÉS, 1998, p. 27). Mas ao mesmo tempo em que a história literária fornece modelos ou exemplos a serem imitados, ela também é fonte de inspiração e criação. Se a literatura fosse pura e exclusivamente imitativa, produziria obras repetitivas e pouco atrativas para os leitores: seria, enfim, sempre a mesma. 
A relação de dívida com os escritores do passado passou a ser abalada com o surgimento do Romantismo e com a nova visão de história instaurada pela Revolução Francesa: a história é guiada pela mudança e pelo progresso. A tradição literária não serve mais como bússola para o fazer artístico; é o novo, o original e o singular que se transformam em valores a serem perseguidos e conquistados. O passado literário, representado pela Antiguidade Clássica, ameaça desmoronar.

Uma das discussões e polêmicas em torno da literatura moderna, a partir do século XIX, é, portanto, sua relação ambígua e contraditória com a tradição. A história da modernidade que, ao que tudo indica, entrará para a posteridade, é uma história de contradições e paradoxos. Tudo parece ter começado com Baudelaire, no Saláo de 1845, ao proclamar como palavra de ordem o novo. Essa nova estética desvela, em contrapartida, um rompimento com o passado e com o estilo clássico - é uma negação da tradição. O novo aparece como critério de valor e está intimamente associado ao conceito de ruptura; uma atitude de pensamento que, portanto, nasceu com o espírito romântico, desenvolveu-se com Baudelaire e foi consolidada intensamente na modernidade.

Para Eliot (1989) a busca por encontrar em uma obra literária o que é individual e singular, o que faz um escritor diferenciar-se de todos seus antecessores, não passa de um preconceito: "Ao contrário, se nos aproximarmos de um poeta sem esse preconceito, poderemos amiúde descobrir que não apenas o melhor mais também as passagens mais individuais de sua obra podem ser aquelas em que os poetas mortos, seus ancestrais, revelam mais vigorosamente sua imortalidade" (ELIOT, 1989, p. 38).

Não se trata de fazer dos caminhos da tradição o único caminho a ser seguido. Para Eliot, a tradição tem um significado muito mais amplo, pois ela não pode ser herdada e sim conquistada. A tradição implica o conhecimento do sentido histórico, a percepção "não apenas da caducidade do passado, mas de sua presença" (ELIOT, 1989, p. 39). Nenhum escritor tem sua significação completa sozinho, mas como parte de uma tradição e o valor que lhe atribuímos está associado ao conhecimento literário que temos.

A história literária muitas vezes assume uma perspectiva sincrônica que desconhece o progresso na literatura. Na verdade, não há progresso e sim mudanças. É certo que a literatura não é a mesma do tempo de Homero: "a literatura muda porque a história muda em torno dela. Literaturas diferentes correspondem a momentos históricos diferentes" (COMPAGNON, 2001, p. 196). É possível comparar e admitir progresso entre um automóvel 
do início do século XX e uma Ferrari, porém é um equívoco afirmar que a poesia de Fernando Pessoa representa progresso em relação a Horácio. É a mentalidade que muda, e essa mudança "é um desenvolvimento que nada abandona em route, que não aposenta nem Shakespeare nem Homero, nem os desenhos rupestres do artista magdaleniano" (ELIOT, 1989, p. 41). Shakespeare era lido em sua época provavelmente de maneira diferente da de hoje: são Shakespeare diferentes, mas enfim, é o mesmo Shakespeare. Não há um aperfeiçoamento em arte ou literatura, apenas hoje temos uma consciência do passado. $O$ próprio fato de a arte primitiva servir de inspiração e modelo para as vanguardas do início do século XX pode ser considerado um indício da inexistência de progresso na arte.

A tradição vista como fonte recriadora, e não como um conjunto de grilhões, traz à tona a ideia do novo e da originalidade, conceitos que, como já mencionamos, tornaram-se valores a partir do Romantismo. "Foi vencida a tirania do classicismo normal. A obediência às regras e a imitação dos autores modelares já não conferem direito a uma boa qualificação. Só importam os espíritos criadores. Com isso não se abandona, mas se modifica o conceito de tradição" (CURTIUS, 1996, p. 483-484). Nessa nova postura de ver a tradição não significa que o novo não existia ou não fazia parte da composição artística. A estética do novo "sempre existiu. Sim, no sentido de uma estética da surpresa e do inesperado, como no barroco, mas não no sentido de uma estética da mudança e da negação" (COMPAGNON, 1996, p. 20). Ou ainda, como acrescenta Paz, "na arte clássica a novidade era uma variação do modelo; na barroca, uma exageração; na moderna, uma ruptura. Nos três casos a tradição vivia como uma relação, polêmica ou não, entre o antigo e o moderno: o diálogo das gerações não se rompia (COMPAGNON ,1996, p. 134).

Nesse sentido, a imitação era antes vista como um dever, como algo legítimo que, no entanto, não excluía o surgimento de obras originais. Mesmo na modernidade as ideias de novo e originalidade devem ser usadas com cautela, pois são conceitos igualmente relativos e históricos - a novidade tende a tornar-se tradição, como o romantismo tende a tornar-se classicismo, o que nos leva a crer que aquilo que denominamos de ruptura atualmente era, antes, designado de variação ou exageração - são as velhas ideias com novos nomes.

Outro tema fundamental da modernidade, ao lado de sua relação contraditória com a tradição é a que envolve o conceito de originalidade, pois se há ruptura há então, originalidade. A questão que se levanta atualmente entre os teóricos é a de que, em se tratando de literatura, não há originalidade. "Na verdade, uma obra literária já não pode ser considerada 
original; se o fosse, não poderia ter sentido para seu leitor. É apenas como parte de discursos anteriores que qualquer texto obtém sentido e importância" (HUTCHEON, 1991, p. 166). Para se entender um texto literário, o leitor volta-se para sua própria memória cultural e literária, aos seus conhecimentos de leitura. Assim, ao visualizar um texto em versos ele sabe previamente que tipo de texto irá encontrar; sabe que o texto se diferencia da prosa e do drama e, possivelmente, terá uma significação determinada, parecida com algo que ele já conheça.

Modernamente as noções de originalidade, subjetividade e criatividade têm sido questionadas. "O artista vive na contradição: quer imitar e inventa, quer inventar e copia. Se os artistas contemporâneos aspiram a ser originais, únicos e novos, deveriam começar por colocar entre parêntesis as ideias de originalidade, personalidade e novidade: são os lugares-comuns do nosso tempo" (PAZ, 1996, p. 135). A crença na originalidade sofreu um golpe, talvez fatal, com a introdução do termo intertextualidade nos estudos literários. A concepção de que os textos só podem variar a partir de mensagens primeiras e estas oferecem possibilidades de variação tornou-se o fundamento atual da literatura. Toda a literatura, mesmo a da Antiguidade, é uma mensagem segunda. Os próprios modelos são, nesse sentido, "mensagens segundas". As "traduções, imitações ou outras formas de retomada de um texto não devem ser vistas como fenômenos à parte, 'derivados' e 'menores', distintos em sua natureza das obras 'originais" (ACHCAR, 1994, p. 55).

O termo intertextualidade passou a ser empregado sistematicamente a partir do século XX. A concepção de que um texto está entrelaçado a outro, de que uma palavra retoma outra já dita e, portanto, "não é fácil encontrar as portas das palavras não-ditas" (Baquílides), surgiu no pensamento teórico a partir dos estudos de Bakhtin. Para ele as palavras nunca são neutras ou vazias; elas são unidades migratórias, ou seja, uma palavra migra de um discurso a outro levando consigo seu contexto inicial e de passagem.

\begin{abstract}
A palavra não é um objeto, mas um meio constantemente ativo [...]. Ela nunca basta a uma consciência, a uma voz. Sua vida está na passagem de boca em boca, de uma geração para outra. Nesse processo ela não perde o seu caminho nem pode liberta-se até o fim do poder daqueles contextos concretos que integrou [...]. A palavra ele [um membro de um grupo falante] a recebe da voz de outro e repleta de voz de outro. No contexto dele, a palavra deriva de outro contexto, é impregnada de elucidações de outros. O próprio pensamento dele já encontra a palavra povoada (BAKHTIN, 1997, p. 203).
\end{abstract}


Para Bakhtin as palavras jamais estão vazias; elas sempre estão impregnadas da voz do outro e é isto que lhes garantem vivacidade. As palavras de um texto retomam outras já ditas, já escritas, e todo esse processo da palavra, do modelo ao texto segundo, não deve ser esquecido pelo leitor, pois ele é o responsável pelo elo entre o texto do passado e o texto atual, comprovando a argumentação de Perrone-Moisés (1998, p. 20) de que foi a estética da recepção, a partir de Jauss, que promoveu o verdadeiro renascimento da história literária.

A intertextualidade literária, o "fenômeno de um texto retomar outro, por meio de citações, alusões, inversões, paródicas ou não" (ACHCAR, 1994, p. 13), a partir dos estudos de Bakhtin, passou a ser parte essencial do discurso literário ou, até mesmo, condição inerente para explicar o fazer artístico. A “ 'literariedade' de uma obra, sua pertinência a um gênero, mesmo sua novidade, são necessariamente produto de suas relações com obras anteriores, presentes nela em alusões implícitas ou explícitas, intencionais ou não" (ACHCAR, 1994, p. 15).

o próprio conceito de literatura pode, assim, ser definido como "o discurso voltado para a alusão, ou mais propriamente, para a 'reutilização' de discursos precedentes" (ACHCAR, 1994, p. 16). E se a literatura é por definição linguagem carregada de sentido, os textos intertextuais são sobrecarregados de significação, pois eles superpõem ao contexto das palavras utilizadas um outro contexto - parte-se da tradição literária para criar um outro contexto.

Nesse sentido, a tradição histórica está, consciente ou não, presente no fazer artístico do escritor. Ele retoma outros textos, faz alusões, citações, paródias, enfim, retoma toda uma memória textual - a tradição - no momento da criação. Também ela está presente no ato de leitura: o leitor faz inferências e retoma textos já lidos para construir a significação textual; faz uso de sua bagagem cultural e literária.

Diante da intertextualidade, do fato de que não há originalidade e de que os poemas falam de outros poemas, podemos pensar se a literatura é imitação da natureza ou da própria literatura. Frye (2000, p. 48) discute este fato ao apresentar as convenções literárias como "natureza metodizada" e o engenho como "natureza favoravelmente adornada" Assim, Frye nos diz que é "possível que Virgílio tenha imitado a natureza; é certo que imitou Homero" pois conclui mais adiante que, afinal, Homero e a natureza são a mesma coisa. Ele nos remete, assim, às ideias de originalidade e de criatividade. Para ele a natureza, a realidade ou a experiência não podem ser a causa formal da arte, nem o impulso de dar forma literária a algo só pode vir de um contato anterior com a literatura.

A forma literária, portanto, está no interior da poesia, sendo a 
poesia não um simples conjunto de poemas, mas um conjunto de formas e de categorias ao qual cada novo poema se junta, em algum lugar (ACHCAR, 1994). Dessa forma, a literatura, assegura Achcar, é compreendida como uma "sociedade verbal" de natureza alusiva, pois suas formas só podem derivar de outras formas literárias. Diante de tais perspectivas, há que se considerar que uma das demonstrações de que o passado permanece vivo e a literatura nasce da própria literatura é a permanência de temas ou lugarescomuns nos textos atuais, ou seja, os topoi.

Um dos estudos mais importantes sobre a continuidade dos temas ou topoi da Antiguidade é a obra de Curtius, A Literatura Européia e a Idade Média Latina, publicado em 1948. Esse estudo mobilizou e ainda mobiliza a reflexão sobre a sobrevivência dos topoi na literatura e nos leva a um questionamento: seria a história da literatura uma história da tradição? A arte ainda hoje não deixou de ser imitação? Ou a reflexão poderia ser formulada de outra maneira, de acordo com os pressupostos formalistas: a literatura é antes uma história de automatismo e continuidade do que de estranhamento e desfamiliarização? Enquanto Curtius busca verificar a continuidade da tradição na literatura, os formalistas enfatizam e propõem uma nova história literária: a história da ruptura - o que faz cada texto ser considerado literatura e ter literariedade é seu caráter desfamiliar, único e novo, ideia impulsionada pelo estilo modernista e pelas vanguardas.

Os topoi, termo que ficou conhecido e passou a ser empregado como sinônimo de lugar comum, espécie de estereótipos universais, termo assimilado da retórica, na qual "eram não só a matéria dos argumentos como também os lugares-comuns formais (loci communes) empregados pelos oradores na composição dos seus discursos" (MOISÉS, 1992, p. 494), passaram a ser a encarnação da tradição: os topoi revelam, num sentido amplo, a sobrevivência do passado e o adiantamento da ruptura. Na retórica, a tópica correspondia aos mais variados pensamentos e podiam ser empregados em qualquer discurso e escrita, como uma espécie de "celeiro das provisões", segundo Curtius (1996). De acordo com seu pensamento, ainda, nem todos os topoi se originaram da retórica, alguns derivaram da poesia e, posteriormente, foram incorporados à retórica, indicando uma permanente aproximação entre prosa e poesia. Ao buscar uma "unidade de sentido" ou uma unidade da cultura ocidental, de Homero a Goethe, através de textos literários que levam em consideração o tempo e o espaço, Curtius estabeleceu a tópica como o lugar da continuidade histórica, por meio de certas formas consideradas como lugares-comuns e que, nascidas na Antiguidade, circularam depois da Renascença.

Entre as tópicas descritas por Curtius estão, entre outras, a da falsa modéstia, invocação à natureza, o mundo às avessas, menino e ancião 
e anciã e menina. Elas são retomadas e desvelam a continuidade histórica, seu constante renascimento e desaparecimento. "Como toda vida, a tradição é um interminável fenecimento e renovação" (CURTIUS, 1996, p. 479). Os topoi distanciam, de um modo geral, os poetas das noções de inspiração divina, criação única e singular, e os aproximam da tradição herdada, da história literária. Imitar os antigos ou os modelos universais é, de certa maneira, uma garantia contra a decadência da literatura.

Dentre os muitos constantes topoi da história literária, está o carpe diem, talvez o mais apreciado e cultuado pelos escritores e, por isso, certamente o mais conhecido e reconhecido pelos leitores. Tomaremos como ponto de partida a teoria de Achcar (1994), que propõe uma genealogia do carpe diem, considerando-o um gênero poético, desde Homero até o século XX. Segundo Achcar, maioria dos críticos define o gênero lírico a partir de elementos como o eu, aqui, agora; o presente, a brevidade da canção e o tom emotivo do sujeito. A lírica, com isso, está voltada para o dia, a efemeridade e esses aspectos seminais da lírica são compartilhados pelo homem, pois ele também está sujeito à transitoriedade e à instantaneidade da vida. Além de constituir uma característica essencial do gênero lírico, a fugacidade do tempo é um topos presente no escritor lírico mais antigo que conhecemos: Arquíloco, do início do século VII a.C. (ACHCAR, 1994, p 61). O tema, posteriormente, é utilizado por vários poetas do período helenístico e romano, durante a Idade Média, o Classicismo e o Barroco, até ser aparentemente relegado pelos românticos e modernistas.

Os escritores romanos também cultivaram a poesia do carpe diem; "sem dúvida teve importância nessa aceitação o pragmatismo característico da sociedade romana, incluíndo aí seu estoicismo, sua consideração desidealizada da existência [...] o enriquecimento cultural e histórico" (ACHCAR, 1994, p. 74). Em Roma, o gênero iniciou-se com Catulo e é dele o exemplo mais extraordinário e característico: o poema 5 "Vivamos, minha Lésbia, e amemos". Embora esse poema seja um representante indiscutível do carpe diem, "a lírica de Horácio desperta mais atenção que a de Catulo e as modulações horacianas do tema hedonista encontraram numerosos intérpretes" (ACHCAR, 1994, p. 77).

Horácio foi contemporâneo e amigo pessoal de Virgílio. Publicou as Odes (Carmina) entre os anos 30 e 23 a.C. e são consideradas "o ponto culminante de seu esforço lírico", nelas o poeta "canta a juventude, o amor, os prazeres do vinho, a alegria da vida; dirige-se aos deuses, relembra lendas mitológicas, exalta o civismo e o espírito patriótico" (CARDOSO, 1989, p. 67). Nas Odes estão presentes as principais ideias horacianas, "retomadas, mais tarde, pela poesia de todas as épocas". 
O poema de Horácio representativo do carpe diem é a ode 11 que trascrevemos abaixo a partir da tradução de Achcar (1994):

\begin{abstract}
Tu não indagues (é ímpio saber) qual o fim que a mim e a ti os deuses tenham dado, Leuconoé, nem recorras aos números babilônicos. Tão melhor é suportar o que será! Quer Júpiter te haja concedido muitos invernos, quer seja o último o que agora debilita o mar Tirreno nas rochas contrapostas, que sejas sábia, coes os vinhos e, no espaço breve, cortes a longa esperança. Enquanto estamos falando, terá fugido o tempo invejoso; colhe o dia, quanto menos confiada no de amanhã (1994, p. 88).
\end{abstract}

Segundo Achcar, essa ode não foi motivo de muita atenção e estudos durante um longo tempo e apenas recentemente ela tem sido objeto merecido de estudo. No poema, aparecem algumas características e essências da poesia do carpe diem, associados ainda à lírica simpótica - a lírica do tu. Desta última, citamos o sujeito dialogante (o enunciador), seu interlocutor (o enunciatário) e a exortação (o enunciado de orientação conativa); especificamente do carpe diem, temos o convite ao prazer ou convite amoroso, a crença na astrologia, o próprio carpe diem e o spatio breui.

o enunciador é o próprio eu lírico que aparece marcado singularmente no pronome mim e também, juntamente, com o interlocutor no verbo estamos; este, por sua vez, é apresentado de maneira direta através de seu próprio nome: Leuconoé, aparece, ainda, nos pronomes $t u, t i$ e te. Já a exortação pode ser identificada nos verbos: sejas, coes, cortes e colhe, e nos verbos acompanhados de negação: não indagues e nem recorras.

Dentre essas várias exortações hedonistas, a que nos interessa é a do carpe diem - uma imagem que "a repetição mecânica nos fez quase insensíveis" (ACHCAR, 1994, p. 92). O verbo carpere tem sua significação, geralmente aceita, associada a fruir, gozar. Achcar, adotando a visão do teórico Traina, estabelece que o verbo está entre duas trincheiras: tomar e colher: a "differencia specifica é o sentido de 'destacar', de separar uma parte de um todo ou fazê-lo em partes" (ACHCAR, 1994, p. 94), ou num movimento que vai do todo às partes. Dessa forma, a parte pressuposta no poema é o dia e o todo tempo: numa "ação mais vigorosa e decidida do que 'delicada': pegar o dia, apanhar o tempo concreto, destacando-o do abstrato tempo da vida" (ACHCAR, 1994, p. 94).

Quanto ao outro indício de efemeridade no texto - spatio breui-o sentido mais recorrente é o de ablativo de lugar com conotação temporal, significando no espaço breve, espécie de metáfora espacial do tempo e condição geral da existência. Ou ainda a expressão pode ser interpretada 
como um ablativo absoluto, no sentido de "sendo breve a vida" (ACHCAR, 1994, p. 94).

Outro fundamento importante do poema é o convite amoroso, cujo representante mais antigo é o poema 5 de Catulo que já mencionamos; a justificativa do convite é sempre a passagem e a brevidade do tempo. No poema de Horácio trata-se de um convite ao prazer, formulado a partir da exortação. Surge primeiro, com a expressão sejas sabia, numa alusão à Leuconoé ser prudente e aproveitar a vida; depois aparece coes os vinhos, que para a maioria dos comentadores não passa de um "esclarecimento sobre o hábito romano de coar os vinhos antes de os beber, purificando-os assim da borra" (ACHCAR, 1994, p. 92) e pode sugerir consumo imediato, como se aconselhasse coá-lo agora e bebê-lo no presente, sem deixá-lo para amanhã, já que este é incerto.

Também é importante no texto de Horácio a simulação do diálogo entre o eu lírico e o interlocutor, indício básico da poesia simpótica. Há uma encenação dialógica entre o enunciador e Leuconoé. Esta, apesar das dúvidas e incertezas que giram ao seu redor, parece ser uma mulher de espírito ingênuo que acredita ou confia em astrologia - a crença na astrologia é índice da poesia do carpe diem.

Horácio transformou a ode ad Leuconoé em um topos do gênero carpe diem, demonstrando a brevidade do tempo e da vida; aconselha a aproveitar o dia sem se fiar no amanhã: propõe a fruição do presente e desconsidera tudo que possa impedir essa fruição, como "as preocupações com o futuro, as 'questões severas' da vida pública, a preocupação com a riqueza, o apego aos bens" (ACHCAR, 1994, p. 97). Tornou-se um topos tão intensamente cultuado que correu o risco de tornar-se invisível.

Veremos, agora, como o carpe diem está presente na literatura moderna, configurando-se nos topoi. Assim, buscamos refletir sobre a permanência de uma tradição ou a instauração de uma ruptura na história literária, estabelecendo uma relação entre o carpe diem e a poesia brasileira do século XX. Os poemas e os versos selecionados são da escritora mineira, surgida na década de 70: Adélia Prado. O poema selecionado pertence a seu livro A faca no peito (1988), e em sua Poesia reunida (1999). Os temas constantes em sua poesia são a religiosidade, a morte, a província mineira e o amor.

O tema do carpe diem aparece em diversos textos de sua obra poética. Neles, o eu lírico constata a efemeridade da vida e sugere gozar a vida em todos os seus momentos. Citamos alguns versos para comprovar essa afirmação: 
Que noite tão clara e quente,

ó vida tão breve e boa!

(Bagagem, 1976)

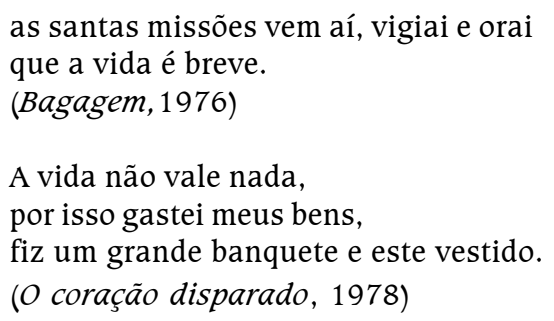

Nos dois primeiros fragmentos temos a recorrência da brevidade da vida - uma reminiscência do carpe diem horaciano; no terceiro aparece um elemento importante: o desapego aos bens materiais ("gastei meus bens") e a sugestão em aproveitar a vida com "um grande banquete" e um "vestido", prazeres hedonistas, representando a vaidade e até mesmo algo passageiro - se a vida não vale nada, se é efêmera, devemos aproveitá-la com intensidade; Em vários outros poemas temos a recorrência da efemeridade da vida e, portanto, uma retomada do gênero do carpe diem, comprovando que os poemas falam de outros poemas e que o tema horaciano continua vivo em nossa literatura.

Reafirmando essa constatação, no poema $O$ encontro, de Adélia Prado, temos os elementos básicos da poesia simpótica. Em primeiro lugar o enunciador, o eu lírico, identificado pelo pronome pessoal minha e meu e pelos verbos em primeira pessoa: Acompanhei, contornei, bati, Pedi; está implícito, ainda, nos verbos da terceira pessoa do plural: resolvermos, resistiríamos, Vamos e no pronome nos. Nestas últimas expressões é possível identificar também o enunciatário, a quem se destina o convite: Jonathan semelhança com o poema de Horácio, pois nele o destinatário surge identificado pelo nome próprio, Leuconoé; o enunciatário no poema de Adélia Prado está, ainda, marcado textualmente pelos pronomes teu e tua.

Outro elemento essencial é a exortação: o enunciado de valor conativo, no sentido de ordem ou conselho, pode estar sugerido nos seguintes verbos: Pedi, faz, Vamos e no advérbio temporal Agora, reforçando a caráter preeminente da exortação hedonista - aproveitar ou colher o instante breve - a parte - do tempo - do todo. A característica, portanto, da poesia simpótica está representada pela encenação dialógica que, como vimos, é um indício básico do gênero do carpe diem. É interessante observar que o destinatário do poema não é uma dama, não se trata de uma Lésbia ou Leuconoé; as posições são invertidas, pois, agora, o destinatário é masculino, Jonathan, 
e o eu lírico feminino.

\author{
Jonathan, \\ se resolvermos que o céu \\ é este lugar onde ninguém nos ouve, \\ quem poderá salvar-no?
}

o carpe diem está, também, identificado pelo convite amoroso - o próprio título do poema, $O$ encontro, desvela a sugestão do convite. $O$ eu lírico faz um apelo ao enunciatário para que ambos possam aproveitar o momento antes que o tempo passe e a velhice chegue, "antes que o corpo alardeie/ sua mísera condição", ou seja, induz a viver com prazer o instante, uma maneira de vencer o tempo pela própria imersão no instante; instiga Jonathan a viver e gozar da vida no momento presente, Agora, que é o instante breve, mas perfeito. $O$ caráter passageiro da vida pode estar sugerido, ainda, na constatação da morte e na necessidade de viver o instante: "o amor da morte instigando-nos/ com nunca vista coragem". É como se o instante, fugaz e voraz, fosse transformado, ilusoriamente, em Eternidade. Outro indício do gênero do carpe diem presente no poema $O$ encontro está nos versos iniciais "se resolvermos que o céu/ é este lugar onde ninguém nos ouve,/ quem poderá salvar-nos?", uma alusão à crença no céu e em Deus. Enquanto no poema de Horácio o eu lírico adverte Leuconoé sobre a confiança na astrologia, indicando que os astros não podem prever o futuro, o eu lírico do texto de Adélia Prado sugere a fé no catolicismo, pois, segundo este, quem crê no céu ou em Deus poderá ser salvo, ganhar a eternidade e a vida eterna. Se o eu lírico e Jonathan acreditam que podem ser amparados pelo céu, serão salvos e ganharam imortalidade. Como o tema apresenta uma característica anticristã, apontada pelo crítico Antônio Candido (2004), o texto da poeta mineira sugere uma contradição: se existe a fé no catolicismo pela crença na vida eterna, essa crença não impede que o eu lírico goze a vida e aproveite todos os momentos sem se preocupar com a castidade ou a virtude.

Os dois poemas analisados nos mostram algumas semelhanças presentes entre o texto de Horácio e o de Adélia Prado, desvelando algumas afinidades temáticas entre os dois, como o convite amoroso, a brevidade do tempo e da vida, a crença na astrologia ou em algum outro fato espiritual e a permanência de elementos da poesia simpótica, indícios que caracterizam o gênero do carpe diem. A recorrência do tema horaciano nos leva a refletir sobre a permanência de determinados topoi na literatura moderna e, de certa maneira, a duvidar da existência de uma ruptura na história da 
literatura. O carpe diem promoveu, assim, um elo entre o passado e o presente, entre o antigo e o novo. Nos faz compreender que os textos clássicos estão sempre vivos quando um escritor retoma e reconfigura palavras já ditas. Isso quer dizer que a poeta mineira teria consciência dos reflexos do carpe diem em sua escrita. Ao contrário, o que desejamos afirmar é que todo sujeito envolvido com a poesia, leitor de obras literárias de todos os tempo e períodos, que é o caso de Adélia Prado, carrega consigo um espírito quase que universal, um Zeitgeist, que o torna depositário de uma série de temas permanentes na história da Literatura.

As fronteiras entre tradição e ruptura, repetição e novidade não são nítidas nem tampouco possíveis de deslindar. A tradição, compreendendo todo nosso passado textual - os clássicos -, sempre esteve presente na composição artística, mesmo nos momentos em que a literatura foi compreendida como um jogo de oposições e negação com toda a literatura anterior; mesmo quando a criação artística foi impulsionada pelas ideias de originalidade e singularidade e o escritor acreditou ser movido por seu próprio ímpeto criador, pensando ser único e irrepetível.

A singularidade de uma obra, proclamada pelo Romantismo, pôs fim em séculos de arte identificada como imitação de modelos e regras e instaurou uma crise nos estudos históricos. Se a literatura é novidade, aquilo que é novo, ela é irredutível à história e todos os textos escritos antes não alteram os textos posteriores. No século XX, no entanto, sobretudo os estudos sobre intertextualidade, demonstraram que um texto retoma textos anteriores, palavras já ditas, já ocupadas por outras vozes e, nesse processo, o conceito de história literária como ruptura passa a ser questionado, juntamente com os conceitos de originalidade, criatividade e novidade.

Se aceitarmos que os textos falam de outros textos, que a literatura é, enfim, alusiva - um texto infinito - certos temas ou topoi são retomados e relembrados constantemente pelos escritores. Como vimos, um topos recorrente é o gênero do carpe diem, cujo modelo consagrado é o poema de Horácio. Mas mesmo o seu texto é um modelo segundo, pois o tema já era conhecido por Homero que, provavelmente, também já constituía um modelo segundo: nesse caminho, talvez, seja impossível encontrar o pai Adão.

o carpe diem horaciano no instante em que é retomado e resgatado por vários escritores também é reconfigurado num novo poema. Muitas vezes, o tema pode estar inteiramente diluído na tessitura textual que corre o risco de tornar-se imperceptível. Na obra de Adélia Prado, o tema do carpe diem reaparece em vários poemas, focalizando principalmente a brevidade da vida. No texto analisado vimos que o convite amoroso - característica do gênero carpe diem - é o tema principal, justificado pela passagem do tempo, a chegada da velhice e o perigo da morte. 
A concepção de texto como entrecruzamento de textos faz renascer a história literária e, numa perspectiva sincrônica, torna todos os textos de todas as épocas simultâneos. Horácio e Adélia Prado são ao mesmo tempo antigos e novos e podem ser contemporâneos do leitor, porque a poesia, e a literatura, desconhecem datas e o leitor pode ter a cada leitura um texto sempre novo. A tradição pode ser constantemente renovada e essa renovação, denominada ruptura pela modernidade, é o que torna a literatura viva.

\title{
RESUMO
}

A modernidade trouxe uma série de termos que ganharam o sabor da moda: novo, originalidade, criatividade, ruptura. Desde o Romantismo, e cada vez se intensificando mais, a tradição literária parece estar confinada em museus; o passado, representado pelos clássicos, tornou-se objeto de esquecimento. Buscamos, neste artigo, demonstrar que os textos literários modernos, muitas vezes a sua revelia, retomam temas ou lugares-comuns da literatura clássica, os topoi. É com esse olhar que examinamos no poema $\mathrm{O}$ encontro, de Adélia Prado, o carpe diem horaciano, consagrado no poema ad Leuconoen. Palavras-chave: Tradição; Ruptura; Carpe Diem.

\begin{abstract}
The modernity brought a series of terms that won the flavor of the moment: new, originality, creativity, rupture. Since "Romantismo", and every time intensifying plus, the literary tradition seems to be confined at museums; the past, represented by the classic, it became object of forgetfulness. We looked for, in this article, to demonstrate that the texts modern, a lot of literary times your "revelia", retake themes or "lugar-comum" of the classic literature, the topoi. It is with that glance that we examined in the poem "O encontro", of Adélia Prado, the carpe diem horaciano, consecrated in the poem "ad Leuconoen".

Keywords: Tradition; Rupture; Carpe Diem.
\end{abstract}




\section{REFERÊNCIAS}

ACHCAR, Francisco. Lírica e lugar-comum: alguns temas de Horácio e sua presença em português. São Paulo: Edusp, 1994.

BAKHTIN, Mikhail. Problemas da poética de Dostoiévski. Tradução de Paulo Bezerra. 2. ed. Rio de Janeiro: Forense Universitária, 1997.

CANDIDO, Antônio. O observador literário. 3. ed. Rio de Janeiro: Ouro sobre Azul, 2004.

CURTIUS, Ernst Robert. Literatura européia e idade média latina. Tradução de Teodoro Cabral e Paulo Rónai. São Paulo: Hucitec: Edusp, 1996.

CARDoso, Zélia de Almeida. A literatura latina. Porto Alegre: Mercado Aberto, 1989.

COMPAGNON, Antoine. Os cinco paradoxos da modernidade. Tradução de Cleonice P. Mourão, Consuelo F. Santiago e Eunice D. Galéry. Belo Horizonte: UFMG, 1996.

. O demônio da teoria. Literatura e senso comum. Tradução de Cleonice Paes Barreto Mourão, Consuelo Fontes Santiago. 2. ed. Belo Horizonte: Ed. UFMG, 2003.

ELIOT, T. S. Ensaios. Tradução de Ivan Junqueira. Rio de Janeiro: Art Editora, 1989.

FRYE, Northrop. Fábulas de identidade: estudos de mitologia poética. Tradução de Sandra Vasconcelos. São Paulo: Nova Alexandria, 2000.

HUTCHEON, Linda. Poética do pós-modernismo. Tradução de Ricardo Cruz. Rio de Janeiro: Imago, 1991.

MOISÉS, Massaud. Dicionário de termos literários. São Paulo: Cultrix, 1992.

PAZ, Octavio. Os signos em rotação. Tradução de Sebastião Uchoa Leite. São Paulo: Perspectiva, 1996.

PERRONE-MOISÉS, Leyla. A falência da crítica: um caso limite: Lautréamont. São Paulo: Perspectiva, 1973.

Altas literaturas: escolha e valor na obra crítica de escritores modernos. São Paulo: Companhia das Letras, 1998.

PRADO, Adélia. A faca no peito. Rio de Janeiro: Record, 1988. Poesia completa. 9. ed. São Paulo: Siciliano, 1991. Poesia reunida. São Paulo: Arx, 1999.

Submetido em: 14/08/2007.

Aceito em: 25/11/2008. 